\title{
The Existence Theorems of an Optimal Approximate Solution for Generalized Proximal Contraction Mappings
}

\author{
Wutiphol Sintunavarat ${ }^{1}$ and Poom Kumam ${ }^{2}$ \\ ${ }^{1}$ Department of Mathematics and Statistics, Faculty of Science and Technology, Thammasat University Rangsit Center, \\ Pathumthani 12121, Thailand \\ ${ }^{2}$ Department of Mathematics, Faculty of Science, King Mongkut's University of Technology Thonburi (KMUTT), \\ Bangkok 10140, Thailand
}

Correspondence should be addressed to Poom Kumam; poom.kum@kmutt.ac.th

Received 3 June 2013; Accepted 31 July 2013

Academic Editor: Calogero Vetro

Copyright (C) 2013 W. Sintunavarat and P. Kumam. This is an open access article distributed under the Creative Commons Attribution License, which permits unrestricted use, distribution, and reproduction in any medium, provided the original work is properly cited.

Recently, Basha (2011) established the best proximity point theorems for proximal contractions of the first and second kinds which are extension of Banach's contraction principle in the case of non-self-mappings. The aim of this paper is to extend and generalize the notions of proximal contractions of the first and second kinds which are more general than the notion of self-contractions, establish the existence of an optimal approximate solution theorems for these non-self-mappings, and also give examples to validate our main results.

\section{Introduction}

Since Banach's contraction principle [1] first appeared, several authors have generalized this principle in different directions. However, they have shown the existence of a fixed point for self-mappings. One of the most interesting results on Banach's contraction principle is the case of non-self-mappings. In fact, for any nonempty closed subsets $A$ and $B$ of a complete metric space $(X, d)$, a contractive non-self-mapping $T: A \rightarrow$ $B$ does not necessarily have a fixed point $T x=x$. In this case, a best proximity point, that is, a point $x \in A$ for which $d(x, T x)=d(A, B):=\inf \{d(x, y): x \in A \quad y \in B\}$ represents an optimal approximate solution to the equation $T x=x$. It is well known that a best proximity point reduces to a fixed point if the underlying mapping is assumed to be a selfmapping. Consequently, best proximity point theorems are improvement of Banach's contraction principle in case of non-self-mappings.

A classical best approximation theorem was introduced by Fan [2]. Afterward, several authors including Prolla [3], Reich [4], and Sehgal and Singh [5, 6] have derived extensions of Fan's Theorem in many directions. Other works of the existence of a best proximity point for contractive mappings can be found in [7-13]. On the other hand, many best proximity point theorems for set-valued mappings have been established in [14-19]. In particular, Eldred et al. [20] have obtained best proximity point theorems for relatively nonexpansive mappings.

Recently, Basha [21] gave necessary and sufficient conditions to claim the existence of best proximity point for proximal contraction of first and second kinds which are non-selfmapping analogues of contraction self-mappings, and they also established some best proximity theorems. Afterward, several mathematicians extended and improved these results in many ways (see in [22-25]).

The purpose of this paper is to extend and generalize the class of proximal contraction of first and second kinds which are different from another type in the literature. For such mappings, we seek the necessary condition for these classes to have best proximity points and also give some examples to illustrate our main results. The results of this paper are generalizations of results of Basha in [21] and some results of the fundamental metrical fixed point and best proximity point theorems in the literature. 


\section{Preliminaries}

Throughout this paper, suppose that $A$ and $B$ are nonempty subsets of a metric space $(X, d)$. We use the following notations:

$$
\begin{gathered}
d(A, B):=\inf \{d(x, y): x \in A \text { and } y \in B\}, \\
A_{0}:=\{x \in A: d(x, y)=d(A, B) \text { for some } y \in B\}, \\
B_{0}:=\{y \in B: d(x, y)=d(A, B) \text { for some } x \in A\} .
\end{gathered}
$$

Remark 1 . It is easy to see that $A_{0}$ and $B_{0}$ are nonempty whenever $A \cap B \neq \emptyset$. Further, if $A$ and $B$ are closed subsets of a normed linear space such that $d(A, B)>0$, then $A_{0} \subseteq B d r(A)$ and $B_{0} \subseteq B d r(B)$, where $B d r(A)$ is a boundary of $A$.

Definition 2 (see [21]). A mapping $T: A \rightarrow B$ is called a proximal contraction of the first kind if there exists $\alpha \in[0,1)$ such that, for all $a, b, x, y \in A$,

$$
\begin{aligned}
& d(a, T x)=d(A, B), \\
& d(b, T y)=d(A, B)
\end{aligned} \Longrightarrow d(a, b) \leq \alpha d(x, y) .
$$

Remark 3. If $T$ is self-mapping, then $T$ is a proximal contraction of the first kind deduced to $T$ which is a contraction mapping. But a non-self-proximal contraction is not necessarily a contraction.

Definition 4 (see [21]). A mapping $T: A \rightarrow B$ is said to be a proximal contraction of the second kind if there exists $\alpha \in[0,1)$ such that, for all $a, b, x, y \in A$,

$$
\begin{aligned}
& d(a, T x)=d(A, B), \\
& d(b, T y)=d(A, B)
\end{aligned} \Longrightarrow d(T a, T b) \leq \alpha d(T x, T y) .
$$

The necessary condition for a self-mapping $T$ to be a proximal contraction of the second kind is that

$$
d(T T x, T T y) \leq \alpha d(T x, T y)
$$

for all $x, y$ in the domain of $T$. Therefore, every contraction self-mapping is a proximal contraction of the second kind, but the converse is not true (see Example 5).

Example 5. Consider $\mathbb{R}$ endowed with the Euclidean metric. Let the self-mapping $T:[0,1] \rightarrow[0,1]$ be defined as follows:

$$
T(x)= \begin{cases}0 & \text { if } x \text { is rational } \\ 1 & \text { otherwise }\end{cases}
$$

It is easy to prove that $T$ is a proximal contraction of the second kind. However, $T$ is not a contraction mapping.

The above example also exhibits that a self-mapping, that is, a proximal contraction of the second kind, is not necessarily continuous.

Definition 6. Let $S: A \rightarrow B$ and T $: B \rightarrow A$ be mappings. The pair $(S, T)$ is said to be

(1) a cyclic contractive pair if $d(A, B)<d(x, y) \Rightarrow$ $d(S x, T y)<d(x, y)$ for all $x \in A$ and $y \in B$;
(2) a cyclic expansive pair if $d(A, B)<d(x, y) \Rightarrow$ $d(S x, T y)>d(x, y)$ for all $x \in A$ and $y \in B ;$

(3) a cyclic inequality pair if $d(A, B)<d(x, y) \Rightarrow$ $d(S x, T y) \neq d(x, y)$ for all $x \in A$ and $y \in B$.

Definition 7. Let $S: A \rightarrow B$ and $T: B \rightarrow A$ be mappings. The pair $(S, T)$ is said to satisfy min-max condition if, for all $x \in A$ and $y \in B$,

$$
d(A, B)<d(x, y) \Longrightarrow \min (S x, \mathrm{~T} y) \neq \max (S x, T y)
$$

where $\min (S x, T y)$ and $\max (S x, T y)$ are defined by

$$
\begin{gathered}
\min (S x, T y)=\min \{d(x, y), d(x, S x), d(y, T y), \\
d(S x, T y), d(x, S T y), \\
d(y, T S x), d(S x, T S x), \\
d(T y, S T y), d(T S x, S T y)\}, \\
\max (S x, T y)=\max \{d(x, y), d(x, S x), d(y, T y), \\
d(x, T y), d(y, S x), d(S x, T y), \\
d(x, T S x), d(y, S T y), d(x, S T y), \\
d(y, T S x), d(S x, T S x), \\
d(T y, S T y), d(T S x, S T y)\} .
\end{gathered}
$$

We observe that the cyclic contractive pairs, cyclic expansive pairs, and cyclic inequality pairs satisfy the min-max condition.

Definition 8. Let $T: A \rightarrow B$ a mapping and $g: A \rightarrow A$ be an isometry. The mapping $T$ is said to preserve isometric distance with respect to $g$ if

$$
d(\operatorname{Tg} x, \operatorname{Tg} y)=d(\operatorname{Tx}, T y)
$$

for all $x, y \in A$.

Definition 9. A point $x \in A$ is said to be a best proximity point of a mapping $T: A \rightarrow B$ if it satisfies the condition that

$$
d(x, T x)=d(A, B)
$$

Observe that a best proximity reduces to a fixed point if the underlying mapping is a self-mapping.

Definition 10. $A$ is said to be approximatively compact with respect to $B$ if every sequence $\left\{x_{n}\right\}$ in $A$ satisfies the condition that $d\left(y, x_{n}\right) \rightarrow d(y, A)$ for some $y \in B$ has a convergent subsequence.

Remark 11. Any nonempty subset of metric space $(X, d)$ is approximatively compact with respect to itself. 


\section{Main Results}

In this section, we introduce the notions of generalized proximal contraction mappings of the first and second kinds which are different from another type in the literature. We also give the existence theorems of an optimal approximate solution for these mappings.

Definition 12. Let $A, B$ be nonempty subset of metric space $(X, d), T: A \rightarrow B$ and $\mathscr{K}: A \rightarrow[0,1)$. A mapping $T$ is said to be a generalized proximal contraction of the first kind with respect to $\mathscr{K}$ if

$$
\begin{aligned}
& d(a, T x)=d(A, B), \\
& d(b, T y)=d(A, B)
\end{aligned} \Longrightarrow d(a, b) \leq \mathscr{K}(x) d(x, y)
$$

for all $a, b, x, y \in A$.

Remark 13. If we take $\mathscr{K}(x)=\alpha$ for all $x \in A$, where $\alpha \in[0,1)$, then a generalized proximal contraction of the first kind with respect to $\mathscr{K}$ reduces to a proximal contraction of the first kind (Definition 2). In case of a self-mapping, it is apparent that the class of contraction mapping is contained in the class of generalized proximal contraction of the first kind with respect to $\mathscr{K}$ mapping.

Now, we give an example to claim that the class of proximal contraction mapping of the first kind is a proper subclass of the class of generalized proximal contractions of the first kind with respect to $\mathscr{K}$ mapping.

Example 14. Consider the metric space $\mathbb{R}^{2}$ with Euclidean metric. Let $A=\{(0, y):-1<y<1\}$ and $B=\{(1, y)$ : $-1<y<1\}$. Define a mapping $T: A \rightarrow B$ as follows:

$$
T((0, y))=\left(1, \frac{y^{2}}{2}\right)
$$

for all $(0, y) \in A$.

It is easy to check that there is no $\alpha \in[0,1)$ satisfing

$$
d(a, T x)=d(b, T y)=d(A, B) \Longrightarrow d(a, b) \leq \alpha d(x, y)
$$

for all $a, b, x, y \in A$. Therefore, $T$ is not a proximal contraction of the first kind.

Consider a function $\mathscr{K}: A \rightarrow[0,1)$ defined by

$$
\mathscr{K}((0, y))=\frac{|y|+1}{2} .
$$

Next, we claim that $T$ is a generalized proximal contraction of the first kind with respect to $\mathscr{K}$.

If $\left(0, y_{1}\right),\left(0, y_{2}\right) \in A$ such that

$$
\begin{aligned}
& d\left(a, T\left(\left(0, y_{1}\right)\right)\right)=d(A, B)=1, \\
& d\left(b, T\left(\left(0, y_{2}\right)\right)\right)=d(A, B)=1,
\end{aligned}
$$

for all $a, b \in A$, then we have

$$
a=\left(0, \frac{y_{1}^{2}}{2}\right), \quad b=\left(0, \frac{y_{2}^{2}}{2}\right) \text {. }
$$

Therefore, it follows that

$$
\begin{aligned}
d(a, b) & =d\left(\left(0, \frac{y_{1}^{2}}{2}\right),\left(0, \frac{y_{2}^{2}}{2}\right)\right) \\
& =\left|\frac{y_{1}^{2}}{2}-\frac{y_{2}^{2}}{2}\right| \\
& =\left(\frac{\left|y_{1}+y_{2}\right|}{2}\right)\left|y_{1}-y_{2}\right| \\
& \leq\left(\frac{\left|y_{1}\right|+\left|y_{2}\right|}{2}\right)\left|y_{1}-y_{2}\right| \\
& \leq\left(\frac{\left|y_{1}\right|+1}{2}\right)\left|y_{1}-y_{2}\right| \\
& =\mathscr{K}\left(\left(0, y_{1}\right)\right) d\left(\left(0, y_{1}\right),\left(0, y_{2}\right)\right) .
\end{aligned}
$$

This implies that $T$ is a generalized proximal contraction of the first kind with respect to $\mathscr{K}$.

Definition 15. Let $A, B$ be nonempty subset of metric space $(X, d), T: A \rightarrow B$ and $\mathscr{K}: A \rightarrow[0,1)$. A mapping $T$ is said to be a generalized proximal contraction of the second kind with respect to $\mathscr{K}$ if

$$
\begin{aligned}
& d(a, T x)=d(A, B), \\
& d(b, T y)=d(A, B)
\end{aligned} \Longrightarrow d(a, b) \leq \mathscr{K}(x) d(T x, T y)
$$

for all $a, b, x, y \in A$.

Clearly, a proximal contraction of the second kind (Definition 4) is a generalized proximal contraction of the second kind.

Next, we extend the results of Basha [21] and many results in the literature.

Theorem 16. Let $(X, d)$ a complete metric space and $A, B$ be nonempty closed subsets of $X$ such that $A_{0}$ and $B_{0}$ are nonempty. Suppose that $T: A \rightarrow B, g: A \rightarrow A$, and $\mathscr{K}: A \rightarrow$ $[0,1)$ are mappings satisfying the following conditions:

(a) $T$ is a continuous generalized proximal contraction of first kind with respect to $\mathscr{K}$;

(b) $T\left(A_{0}\right) \subseteq B_{0}$ and $A_{0} \subseteq g\left(A_{0}\right)$;

(c) $g$ is an isometry;

(d) $\mathscr{K}(x) \leq \mathscr{K}(y)$, whenever $d(g x, T y)=d(A, B)$.

Then there exists a unique point $x \in A$ such that $d(g x, T x)=$ $d(A, B)$.

Proof. Let $x_{0}$ be a fixed element in $A_{0}$. From $T\left(A_{0}\right) \subseteq B_{0}$ and $A_{0} \subseteq g\left(A_{0}\right)$, it follows that there exists a point $x_{1} \in A_{0}$ such that

$$
d\left(g x_{1}, T x_{0}\right)=d(A, B) .
$$

Again, since $T x_{1} \in T\left(A_{0}\right) \subseteq B_{0}$ and $A_{0} \subseteq g\left(A_{0}\right)$, there exists a point $x_{2} \in A_{0}$ such that

$$
d\left(g x_{2}, T x_{1}\right)=d(A, B) .
$$


Continuing this process, we can construct the sequence $\left\{x_{n}\right\}$ in $A_{0}$ such that

$$
d\left(g x_{n}, T x_{n-1}\right)=d(A, B)
$$

for all $n \in \mathbb{N}$. Since $T$ is a generalized proximal contraction of the first kind with respect to $\mathscr{K}$, it follows that

$$
d\left(g x_{n+1}, g x_{n}\right) \leq \mathscr{K}\left(x_{n}\right) d\left(x_{n}, x_{n-1}\right)
$$

for all $n \in \mathbb{N}$. Also, since $g$ is an isometry, we have

$$
d\left(x_{n+1}, x_{n}\right) \leq \mathscr{K}\left(x_{n}\right) d\left(x_{n}, x_{n-1}\right)
$$

for all $n \in \mathbb{N}$. By using (20) and (d), we have

$$
\begin{aligned}
d\left(x_{n+1}, x_{n}\right) & \leq \mathscr{K}\left(x_{n}\right) d\left(x_{n}, x_{n-1}\right) \\
& \leq \mathscr{K}\left(x_{n-1}\right) d\left(x_{n}, x_{n-1}\right) \\
& \leq \mathscr{K}\left(x_{n-2}\right) d\left(x_{n}, x_{n-1}\right) \\
& \vdots \\
& \leq \mathscr{K}\left(x_{0}\right) d\left(x_{n}, x_{n-1}\right)
\end{aligned}
$$

for all $n \in \mathbb{N}$. By repeating (23), we get

$$
d\left(x_{n+1}, x_{n}\right) \leq\left(\mathscr{K}\left(x_{0}\right)\right)^{n} d\left(x_{1}, x_{0}\right)
$$

for all $n \in \mathbb{N}$. Now, we let $k:=\mathscr{K}\left(x_{0}\right) \in[0,1)$. For positive integers $m$ and $n$ with $n>m$, it follows from (24) that

$$
\begin{aligned}
& d\left(x_{n}, x_{m}\right) \\
& \quad \leq d\left(x_{n}, x_{n-1}\right)+d\left(x_{n-1}, x_{n-2}\right)+\cdots+d\left(x_{m+1}, x_{m}\right) \\
& \quad \leq k^{n-1} d\left(x_{1}, x_{0}\right)+k^{n-2} d\left(x_{1}, x_{0}\right)+\cdots+k^{m} d\left(x_{1}, x_{0}\right) \\
& \quad \leq\left(\frac{k^{m}}{1-k}\right) d\left(x_{1}, x_{0}\right) .
\end{aligned}
$$

Since $k \in[0,1)$, we have $\left(k^{m} /(1-k)\right) d\left(x_{1}, x_{0}\right) \rightarrow 0$ as $m \rightarrow$ $\infty$, which implies that $\left\{x_{n}\right\}$ is a Cauchy sequence in $X$. Since $X$ is complete, it follows that the sequence $\left\{x_{n}\right\}$ converges to point $x \in X$. Since $T$ and $g$ are continuous, we get

$$
d(g x, T x)=\lim _{n \rightarrow \infty} d\left(g x_{n+1}, T x_{n}\right)=d(A, B) .
$$

Next, we suppose that $x^{*}$ is another point in $X$ such that

$$
d\left(g x^{*}, T x^{*}\right)=d(A, B) .
$$

Since $T$ is a generalized proximal contraction of the first kind with respect to $\mathscr{K}$, by using (26) and (27), we get

$$
d\left(g x, g x^{*}\right) \leq \mathscr{K}(x) d\left(x, x^{*}\right) .
$$

Since $g$ is an isometry, it follows that

$$
d\left(x, x^{*}\right) \leq \mathscr{K}(x) d\left(x, x^{*}\right),
$$

which implies that $x=x^{*}$. This completes the proof.
Now, we give an example to illustrate Theorem 16.

Example 17. Consider the complete metric space $\mathbb{R}^{2}$ with Euclidean metric. Let $A=\{(0, y):-1 \leq y \leq 1\}$ and $B=$ $\{(1, y):-1 \leq y \leq 1\}$. Define two mappings $T: A \rightarrow B$ and $g: A \rightarrow A$ as follows:

$$
T((0, y))=\left(1, \frac{y^{2}}{4}\right), \quad g((0, y))=(0,-y)
$$

for all $(0, y) \in A$. Then it is easy to see that $d(A, B)=1$, $A_{0}=A, B_{0}=B$, and the mapping $g$ is an isometry.

Consider a function $\mathscr{K}: A \rightarrow[0,1)$ defined by

$$
\mathscr{K}((0, y))=\frac{|y|+1}{4} .
$$

Next, we claim that $T$ is a generalized proximal contraction of the first kind with respect to $\mathscr{K}$. If $\left(0, y_{1}\right),\left(0, y_{2}\right) \in A$ such that

$$
\begin{aligned}
& d\left(a, T\left(\left(0, y_{1}\right)\right)\right)=d(A, B)=1, \\
& d\left(b, T\left(\left(0, y_{2}\right)\right)\right)=d(A, B)=1,
\end{aligned}
$$

for all $a, b \in A$, then we have

$$
a=\left(0, \frac{y_{1}^{2}}{4}\right), \quad b=\left(0, \frac{y_{2}^{2}}{4}\right) .
$$

Therefore, it follows that

$$
\begin{aligned}
d(a, b) & =d\left(\left(0, \frac{y_{1}^{2}}{4}\right),\left(0, \frac{y_{2}^{2}}{4}\right)\right) \\
& =\left|\frac{y_{1}^{2}}{4}-\frac{y_{2}^{2}}{4}\right| \\
& =\left(\frac{\left|y_{1}+y_{2}\right|}{4}\right)\left|y_{1}-y_{2}\right| \\
& \leq\left(\frac{\left|y_{1}\right|+\left|y_{2}\right|}{4}\right)\left|y_{1}-y_{2}\right| \\
& \leq\left(\frac{\left|y_{1}\right|+1}{4}\right)\left|y_{1}-y_{2}\right| \\
& =\mathscr{K}\left(\left(0, y_{1}\right)\right) d\left(\left(0, y_{1}\right),\left(0, y_{2}\right)\right) .
\end{aligned}
$$

This implies that the non-self-mapping $T$ is a generalized proximal contraction of the first kind with respect to $\mathscr{K}$. It is easy to see that $\mathscr{K}(x) \leq \mathscr{K}(y)$ whenever $d(g x, T y)=d(A, B)$. Moreover, since $T$ is continuous and $g$ is an isometry, all the conditions of Theorem 16 are satisfied, and so $T$ has a unique element $(0,0) \in A$ such that

$$
d(g((0,0)), T((0,0)))=d(A, B) .
$$

Corollary 18 (see [21, Theorem 3.3]). Let $(X, d)$ be a complete metric space and $A, B$ nonempty closed subsets of $X$ such that $A_{0}$ and $B_{0}$ are nonempty. Suppose that $T: A \rightarrow B$ and $g$ : $A \rightarrow A$ are mappings satisfying the following conditions:

(a) $T$ is a continuous proximal contraction of the first kind; 
(b) $T\left(A_{0}\right) \subseteq B_{0}$ and $A_{0} \subseteq g\left(A_{0}\right)$;

(c) $g$ is an isometry.

Then there exists a unique element $x \in A$ such that $d(g x, T x)=$ $d(A, B)$.

Proof. Since a proximal contraction of the first kind is a special case of a generalized proximal contraction of the first kind, we can prove this result by applying Theorem 16 .

In Theorem 16, if $g$ is the identity mapping, then it yields the following best proximity point theorem.

Corollary 19. Let $(X, d)$ a complete metric space and $A, B$ be nonempty closed subsets of $X$ such that $A_{0}$ and $B_{0}$ are nonempty. Suppose that $T: A \rightarrow B$ and $\mathscr{K}: A \rightarrow[0,1)$ are mappings satisfying the following conditions:

(a) $T$ is a continuous generalized proximal contraction of first kind with respect to $\mathscr{K}$;

(b) $T\left(A_{0}\right) \subseteq B_{0}$;

(c) $\mathscr{K}(x) \leq \mathscr{K}(y)$, whenever $d(x, T y)=d(A, B)$.

Then $T$ has a unique best proximity point in $A$.

Corollary 20 (see [21, Corollary 3.4]). Let $(X, d)$ be a complete metric space and $A, B$ nonempty closed subsets of $X$ such that $A_{0}$ and $B_{0}$ are nonempty. Let $T: A \rightarrow B$ be a mapping satisfying the following conditions:

(a) $T$ is a continuous proximal contraction of the first $k i n d$;

(b) $T\left(A_{0}\right) \subseteq B_{0}$.

Then $T$ has a unique best proximity point in $A$.

Proof. Since a proximal contraction of the first kind is a special case of a generalized proximal contraction of the first kind with respect to $\mathscr{K}$, we can prove this result by applying Corollary 19.

Next, we prove the second main result for generalized proximal contraction of the second kind with respect to $\mathscr{K}$ mapping.

Theorem 21. Let $(X, d)$ a complete metric space and $A, B$ be nonempty closed subsets of $X$ such that $A$ is approximatively compact with respect to $B$. Suppose that $A_{0}$ and $B_{0}$ are nonempty and $T: A \rightarrow B, g: A \rightarrow A$, and $\mathscr{K}: A \rightarrow[0,1)$ are mappings satisfying the following conditions:

(a) $T$ is a continuous generalized proximal contraction of the second kind with respect to $\mathscr{K}$;

(b) $T\left(A_{0}\right) \subseteq B_{0}$ and $A_{0} \subseteq g\left(A_{0}\right)$;

(c) $g$ is an isometry;

(d) T preserves isometric distance with respect to $g$;

(e) $\mathscr{K}(x) \leq \mathscr{K}(y)$, whenever $d(g x, T y)=d(A, B)$.

Then there exists a point $x \in A$ such that $d(g x, T x)=d(A, B)$. Moreover, if $x^{*}$ is another point in $A$ for which $d\left(g x^{*}, T x^{*}\right)=$ $d(A, B)$, then $T x=T x^{*}$.
Proof. As in the proof of Theorem 16, for fixed $x_{0} \in A_{0}$, we can define a sequence $\left\{x_{n}\right\}$ in $A_{0}$ such that

$$
d\left(g x_{n}, T x_{n-1}\right)=d(A, B)
$$

for all $n \in \mathbb{N}$. Since $T$ is a generalized proximal contraction of the second kind with respect to $\mathscr{K}$, it follows that

$$
d\left(\operatorname{Tg} x_{n+1}, \operatorname{Tg} x_{n}\right) \leq \mathscr{K}\left(x_{n}\right) d\left(T x_{n}, T x_{n-1}\right) .
$$

Since $T$ preserves isometric distance with respect to $g$, we have

$$
d\left(T x_{n+1}, T x_{n}\right) \leq \mathscr{K}\left(x_{n}\right) d\left(T x_{n}, T x_{n-1}\right)
$$

for all $n \in \mathbb{N}$. By using (36) and (e), we have

$$
\begin{aligned}
d\left(T x_{n+1}, T x_{n}\right) & \leq \mathscr{K}\left(x_{n}\right) d\left(T x_{n}, T x_{n-1}\right) \\
& \leq \mathscr{K}\left(x_{n-1}\right) d\left(T x_{n}, T x_{n-1}\right) \\
& \leq \mathscr{K}\left(x_{n-2}\right) d\left(T x_{n}, T x_{n-1}\right) \\
& \vdots \\
& \leq \mathscr{K}\left(x_{0}\right) d\left(T x_{n}, T x_{n-1}\right)
\end{aligned}
$$

for all $n \in \mathbb{N}$. By repeating (39), we get

$$
d\left(T x_{n+1}, T x_{n}\right) \leq\left(\mathscr{K}\left(x_{0}\right)\right)^{n} d\left(T x_{1}, T x_{0}\right)
$$

for all $n \in \mathbb{N}$. Now, we let $k:=\mathscr{K}\left(x_{0}\right) \in[0,1)$. For positive integers $m$ and $n$ with $n>m$, it follows from (40) that

$$
\begin{aligned}
d\left(T x_{n}, T x_{m}\right) \leq & d\left(T x_{n}, T x_{n-1}\right) \\
& +d\left(T x_{n-1}, T x_{n-2}\right)+\cdots+d\left(T x_{m+1}, T x_{m}\right) \\
\leq & k^{n-1} d\left(T x_{1}, T x_{0}\right)+k^{n-2} d\left(T x_{1}, T x_{0}\right) \\
& +\cdots+k^{m} d\left(T x_{1}, T x_{0}\right) \\
\leq & \left(\frac{k^{m}}{1-k}\right) d\left(T x_{1}, T x_{0}\right) .
\end{aligned}
$$

Since $k \in[0,1)$, we have $\left(k^{m} /(1-k)\right) d\left(T x_{1}, T x_{0}\right) \rightarrow 0$ as $m \rightarrow \infty$, which implies that $\left\{T x_{n}\right\}$ is a Cauchy sequence in $B$. By completeness of $B \subseteq X$, there exists a point $y \in B$ such that $T x_{n} \rightarrow y$ as $n \rightarrow \infty$. By (36) and the triangle inequality, we have

$$
\begin{aligned}
d(y, A) & \leq d\left(y, g x_{n}\right) \\
& \leq d\left(y, T x_{n-1}\right)+d\left(T x_{n-1}, g x_{n}\right) \\
& =d\left(y, T x_{n-1}\right)+d(A, B) \\
& \leq d\left(y, T x_{n-1}\right)+d(y, A) .
\end{aligned}
$$

Letting $n \rightarrow \infty$ in (42), we get $d\left(y, g x_{n}\right) \rightarrow d(y, A)$. Since $A$ is approximatively compact with respect to $B$, it follows that 
$\left\{g x_{n}\right\}$ has a convergence subsequence $\left\{g x_{n_{k}}\right\}$; say $g x_{n_{k}} \rightarrow z \in$ $A$ as $k \rightarrow \infty$. Thus we have

$$
d(z, y)=\lim _{k \rightarrow \infty} d\left(g x_{n_{k}}, T x_{n_{k}-1}\right)=d(A, B),
$$

which implies that $z \in A_{0}$. Since $A_{0} \subseteq g\left(A_{0}\right)$, we have $z=g x$ for some $x \in A_{0}$. Therefore, $g x_{n_{k}} \rightarrow g x$ as $k \rightarrow \infty$. Since $g$ is an isometry, we get $x_{n_{k}} \rightarrow x$ as $k \rightarrow \infty$. By the continuity of $T$, we have $T x_{n_{k}} \rightarrow T x$ as $k \rightarrow \infty$ and then $y=T x$. From (43), we can conclude that

$$
d(g x, T x)=d(A, B)
$$

Next, we suppose that $x^{*}$ is another point in $X$ such that

$$
d\left(g x^{*}, T x^{*}\right)=d(A, B) .
$$

Since $T$ is a generalized proximal contraction of the second kind with respect to $\mathscr{K}$, by the virtue of (44) and (45), we get

$$
d\left(\operatorname{Tg} x, \operatorname{Tg} x^{*}\right) \leq \mathscr{K}(x) d\left(T x, T x^{*}\right) .
$$

Since $T$ preserves isometric distance with respect to $g$, it follows that

$$
d\left(T x, T x^{*}\right) \leq \mathscr{K}(x) d\left(T x, T x^{*}\right)
$$

which implies that $T x=T x^{*}$. This completes the proof.

Corollary 22 (see [21, Theorem 3.1]). Let $(X, d)$ be a complete metric space and $A, B$ nonempty closed subsets of $X$ such that $A$ is approximatively compact with respect to $B$. Suppose that $A_{0}$ and $B_{0}$ are nonempty and $T: A \rightarrow B$ and $g: A \rightarrow A$ are mappings satisfying the following conditions:

(a) $T$ is a continuous proximal contraction of the second kind;

(b) $T\left(A_{0}\right) \subseteq B_{0}$ and $A_{0} \subseteq g\left(A_{0}\right)$;

(c) $g$ is an isometry;

(d) T preserves isometric distance with respect to $g$.

Then there exists a point $x \in A$ such that $d(g x, T x)=d(A, B)$. Moreover, if $x^{*}$ is another point in $A$ for which $d\left(g x^{*}, T x^{*}\right)=$ $d(A, B)$, then $T x=T x^{*}$.

Proof. Since a proximal contraction of the second kind is a special case of a generalized proximal contraction of the second kind with respect to $\mathscr{K}$, we can prove this result by applying Theorem 21.

Corollary 23. Let $(X, d)$ be a complete metric space and $A, B$ nonempty closed subsets of $X$ such that $A$ is approximatively compact with respect to $B$. Suppose that $A_{0}$ and $B_{0}$ are nonempty and $T: A \rightarrow B$ and $\mathscr{K}: A \rightarrow[0,1)$ are mappings satisfying the following conditions:
(a) $T$ is a continuous generalized proximal contraction of the second kind with respect to $\mathscr{K}$;
(b) $T\left(A_{0}\right) \subseteq B_{0}$;
(c) $\mathscr{K}(x) \leq \mathscr{K}(y)$, whenever $d(x, T y)=d(A, B)$.

Then $T$ has a best proximity point. Moreover, if $x^{*}$ is another best proximity point of $T$, then $T x=T x^{*}$.

Proof. We can prove this result by applying Theorem 21 with $g=I_{A}$, where $I_{A}$ is an identity mapping on $A$.

Corollary 24 (see [21, Corollary 3.2]). Let $(X, d)$ be a complete metric space and $A, B$ nonempty closed subsets of $X$ such that $A$ is approximatively compact with respect to $B$. Suppose that $A_{0}$ and $B_{0}$ are nonempty and $T: A \rightarrow B$ is mapping satisfying the following conditions:

(a) $T$ is a continuous generalized proximal contraction of the second kind;

(b) $T\left(A_{0}\right) \subseteq B_{0}$.

Then $T$ has a best proximity point. Moreover, if $x^{*}$ is another best proximity point of $T$, then $T x=T x^{*}$.

Proof. Since a proximal contraction of the second kind is a special case of a generalized proximal contraction of the second kind, we can prove this result by applying Corollary 23 .

Here, we give the last result in this work.

Theorem 25. Let $(X, d)$ be a complete metric space, $A$ and $B$ nonempty closed subsets of $X$, and $\mathscr{K}: A \cup B \rightarrow[0,1)$. Suppose that $S: A \rightarrow B$ is a mapping satisfying

$$
d(S x, S y) \leq \mathscr{K}(x) d(x, y)
$$

for all $x, y \in A$. Then the following holds.

(A) There exists a nonexpansive mapping $T: B \rightarrow A$ such that $(S, T)$ satisfies the min-max condition whenever $S$ has a best proximity point.

(B) If there exists a nonexpansive mapping $T: B \rightarrow A$ such that $(S, T)$ satisfies the min-max condition and $\mathscr{K}(S x) \leq \mathscr{K}(x)$ and $\mathscr{K}(T x) \leq \mathscr{K}(x)$ for all $x \in A$, then $S$ has a best proximity point.

(C) For two any best proximity points $z$ and $z^{*}$ of $S$, we have

$$
d\left(z, z^{*}\right) \leq\left(\frac{2}{1-\mathscr{K}(z)}\right) d(A, B) .
$$

Proof. (A) Let $S$ has a best proximity point $a \in A$. We define a mapping $T: B \rightarrow A$ by $T y=a$ for all $y \in B$. Clearly, $T$ is a nonexpansive mapping. It follows from the definition of $T$ that

$$
d(T y, S T y)=d(a, S a)=d(A, B)
$$

for all $y \in B$. Thus we can conclude that $\min (S x, T y)=$ $d(A, B)$ for all $x \in A$ and $y \in B$.

Next, we show that $(S, T)$ satisfies the min-max condition. Suppose that $x \in A$ and $y \in B$ such that $d(A, B)<d(x, y)$. Then we have

$$
\min (S x, T y)=d(A, B)<d(x, y) \leq \max (S x, T y),
$$


which implies that the pair $(S, T)$ satisfies the min-max condition. Therefore, we can find a nonexpansive mapping $T: B \rightarrow$ $A$ such that $(S, T)$ satisfies the min-max condition.

(B) Fix $x_{0} \in A$ and define a sequence $\left\{x_{n}\right\}$ in $A \cup B$ by

$$
x_{2 n-1}=S x_{2 n-2}, \quad x_{2 n}=T x_{2 n-1}
$$

for all $n \in \mathbb{N}$. Since $T$ is nonexpansive, it follows from (48) that

$$
\begin{aligned}
d\left(x_{2 n-2}, x_{2 n}\right) & =d\left(T x_{2 n-3}, T x_{2 n-1}\right) \\
& \leq d\left(x_{2 n-3}, x_{2 n-1}\right) \\
& =d\left(S x_{2 n-4}, S x_{2 n-2}\right) \\
& \leq \mathscr{K}\left(x_{2 n-4}\right) d\left(x_{2 n-4}, x_{2 n-2}\right) \\
& =\mathscr{K}\left(T x_{2 n-5}\right) d\left(x_{2 n-4}, x_{2 n-2}\right) \\
& \leq \mathscr{K}\left(x_{2 n-5}\right) d\left(x_{2 n-4}, x_{2 n-2}\right) \\
& =\mathscr{K}\left(S x_{2 n-6}\right) d\left(x_{2 n-4}, x_{2 n-2}\right) \\
& \leq \mathscr{K}\left(x_{2 n-6}\right) d\left(x_{2 n-4}, x_{2 n-2}\right) \\
& \vdots \\
& \leq \mathscr{K}\left(x_{0}\right) d\left(x_{2 n-4}, x_{2 n-2}\right)
\end{aligned}
$$

for all $n \in \mathbb{N}$. By repeating the above argument, we have

$$
d\left(x_{2 n-2}, x_{2 n}\right) \leq\left(\mathscr{K}\left(x_{0}\right)\right)^{n-1} d\left(x_{0}, x_{2}\right)
$$

for all $n \in \mathbb{N}$, which implies that the sequence $\left\{x_{2 n}\right\}$ is a Cauchy sequence in $X$. A similar argument asserts that the sequence $\left\{x_{2 n-1}\right\}$ is a Cauchy sequence in $X$. By the completeness of $X$, we conclude that $\left\{x_{2 n}\right\}$ converges to a point $a \in A$ and $\left\{x_{2 n-1}\right\}$ converges to a point $b \in B$. Since $S$ is continuous, $\left\{S x_{2 n}\right\}$ converges to $S a$, which implies that $\left\{x_{2 n-1}\right\}$ converges to $S a$. Thus $S a=b$.

Similarly, it is easy to check that $T b=a$. Therefore, we have

$$
T S a=T b=a, \quad S T b=S a=b .
$$

Now, we can conclude that

$$
\min (S a, T b)=d(a, b)=\max (S a, T b) .
$$

By the virtue of the min-max condition of $(S, T)$, we get $d(a, b) \leq d(A, B)$. Since $d(A, B) \leq d(a, b)$, we have $d(a, b)=$ $d(A, B)$. Therefore, we have

$$
d(a, S a)=d(a, b)=d(A, B),
$$

which implies that $S$ has a best proximity point in $A$.

(C) Let $z$ and $z^{*}$ be best proximity points of $S$. Then $d(z, S z)=d(A, B)$ and $d\left(z^{*}, S z^{*}\right)=d(A, B)$. Using the triangle inequality and (48), we have

$$
\begin{aligned}
d\left(z, z^{*}\right) & \leq d(z, S z)+d\left(S z, S z^{*}\right)+d\left(S z^{*}, z^{*}\right) \\
& \leq \mathscr{K}(z) d\left(z, z^{*}\right)+2 d(A, B) .
\end{aligned}
$$

This implies that $d\left(z, z^{*}\right) \leq(2 /(1-\mathscr{K}(z))) d(A, B)$. This completes the proof.
Corollary 26 (see [21, Theorem 3.6]). Let $(X, d)$ be a complete metric space and $A$ and $B$ nonempty closed subsets of $X$. Suppose that $S: A \rightarrow B$ is a contraction mapping. Then Shas a best proximity point if and only if there exists a nonexpansive mapping $T: B \rightarrow A$ such that $(S, T)$ satisfies the min-max condition.

Moreover, $d\left(z, z^{*}\right) \leq(2 /(1-\alpha)) d(A, B)$ for some $\alpha \in[0,1)$ and any two best proximity points $z$ and $z^{*}$ of $S$.

Proof. Since $S$ is a contraction mapping, we have $d(S x, S y) \leq$ $\alpha d(x, y)$ for some $\alpha \in[0,1)$ and all $x, y \in A$. Now, we can prove this result by applying Theorem 25 with a function $\mathscr{K}$ : $A \cup B \rightarrow[0,1)$ defined by $\mathscr{K}(x)=\alpha$ for all $x \in A \cup B$.

\section{Acknowledgments}

The second author would like to thank the Commission on Higher Education, the Thailand Research Fund, and the King Mongkut's University of Technology Thonburi (Grant no. MRG5580213) for financial support during the preparation of this paper.

\section{References}

[1] S. Banach, "Sur les operations dans les ensembles abstraits et leurs applications aux equations integrales," Fundamenta Mathematicae, vol. 3, pp. 133-181, 1922.

[2] K. Fan, "Extensions of two fixed point theorems of F. E. Browder," Mathematische Zeitschrift, vol. 112, pp. 234-240, 1969.

[3] J. B. Prolla, "Fixed-point theorems for set-valued mappings and existence of best approximants," Numerical Functional Analysis and Optimization, vol. 5, no. 4, pp. 449-455, 1982-1983.

[4] S. Reich, "Approximate selections, best approximations, fixed points, and invariant sets," Journal of Mathematical Analysis and Applications, vol. 62, no. 1, pp. 104-113, 1978.

[5] V. M. Sehgal and S. P. Singh, "A generalization to multifunctions of Fan's best approximation theorem," Proceedings of the American Mathematical Society, vol. 102, no. 3, pp. 534-537, 1988.

[6] V. M. Sehgal and S. P. Singh, "A theorem on best approximations," Numerical Functional Analysis and Optimization, vol. 10, no. 1-2, pp. 181-184, 1989.

[7] M. A. Al-Thagafi and N. Shahzad, "Convergence and existence results for best proximity points," Nonlinear Analysis: Theory, Methods \& Applications A, vol. 70, no. 10, pp. 3665-3671, 2009.

[8] A. A. Eldred and P. Veeramani, "Existence and convergence of best proximity points," Journal of Mathematical Analysis and Applications, vol. 323, no. 2, pp. 1001-1006, 2006.

[9] C. Di Bari, T. Suzuki, and C. Vetro, "Best proximity points for cyclic Meir-Keeler contractions," Nonlinear Analysis: Theory, Methods \& Applications A, vol. 69, no. 11, pp. 3790-3794, 2008.

[10] S. Karpagam and S. Agrawal, "Best proximity point theorems for $p$-cyclic Meir-Keeler contractions," Fixed Point Theory and Applications, vol. 2009, Article ID 197308, 9 pages, 2009.

[11] C. Mongkolkeha, Y. J. Cho, and P. Kumam, "Best proximity points for generalized proximal $C$-contraction mappings in metric spaces with partial orders," Journal of Inequalities and Applications, vol. 2013, article 93, 12 pages, 2013.

[12] C. Mongkolkeha and P. Kumam, "Best proximity points for Geraghty's proximal contraction mapping mappings," Journal of 
Optimization Theory and Applications, vol. 2013, article 180, 12 pages, 2013.

[13] W. Sintunavarat and P. Kumam, "Coupled best proximity point theorem in metric spaces," Fixed Point Theory and Applications, vol. 2012, article 93, 16 pages, 2012.

[14] W. A. Kirk, S. Reich, and P. Veeramani, "Proximinal retracts and best proximity pair theorems," Numerical Functional Analysis and Optimization, vol. 24, no. 7-8, pp. 851-862, 2003.

[15] S. S. Basha and P. Veeramani, "Best proximity pairs and best approximations," Acta Scientiarum Mathematicarum, vol. 63, no. 1-2, pp. 289-300, 1997.

[16] S. S. Basha and P. Veeramani, "Best proximity pair theorems for multifunctions with open fibres," Journal of Approximation Theory, vol. 103, no. 1, pp. 119-129, 2000.

[17] S. S. Basha, P. Veeramani, and D. V. Pai, "Best proximity pair theorems," Indian Journal of Pure and Applied Mathematics, vol. 32, no. 8, pp. 1237-1246, 2001.

[18] K. Włodarczyk, R. Plebaniak, and A. Banach, "Best proximity points for cyclic and noncyclic set-valued relatively quasiasymptotic contractions in uniform spaces," Nonlinear Analysis: Theory, Methods \& Applications A, vol. 70, no. 9, pp. 3332-3341, 2009.

[19] K. Włodarczyk, R. Plebaniak, and A. Banach, "Erratum to: best proximity points for cyclic and noncyclic set-valued relatively quasi-asymptotic contractions in uniform spaces," Nonlinear Analysis: Theory, Methods \& Applications A, vol. 71, pp. 35833586, 2009.

[20] A. A. Eldred, W. A. Kirk, and P. Veeramani, "Proximal normal structure and relatively nonexpansive mappings," Studia Mathematica, vol. 171, no. 3, pp. 283-293, 2005.

[21] S. S. Basha, "Best proximity point theorems," Journal of Approximation Theory, vol. 163, no. 11, pp. 1772-1781, 2011.

[22] J. Caballero, J. Harjani, and K. Sadarangani, "A best proximity point theorem for Geraghty-contractions," Fixed Point Theory and Applications, vol. 2012, article 231, 9 pages, 2012.

[23] W. Sanhan, C. Mongkolkeha, and P. Kumam, "Generalized proximal $\psi$-contraction mappings and best proximity points," Abstract and Applied Analysis, vol. 2012, Article ID 896912, 19 pages, 2012.

[24] T. Suzuki, M. Kikkawa, and C. Vetro, "The existence of best proximity points in metric spaces with the property UC," Nonlinear Analysis: Theory, Methods \& Applications A, vol. 71, no. 7-8, pp. 2918-2926, 2009.

[25] C. Vetro, "Best proximity points: convergence and existence theorems for p-cyclic mappings," Nonlinear Analysis: Theory, Methods \& Applications A, vol. 73, no. 7, pp. 2283-2291, 2010. 


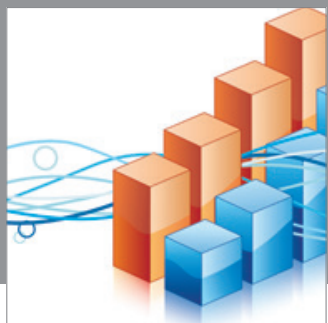

Advances in

Operations Research

mansans

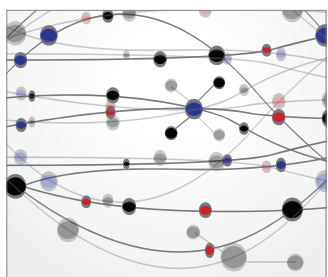

The Scientific World Journal
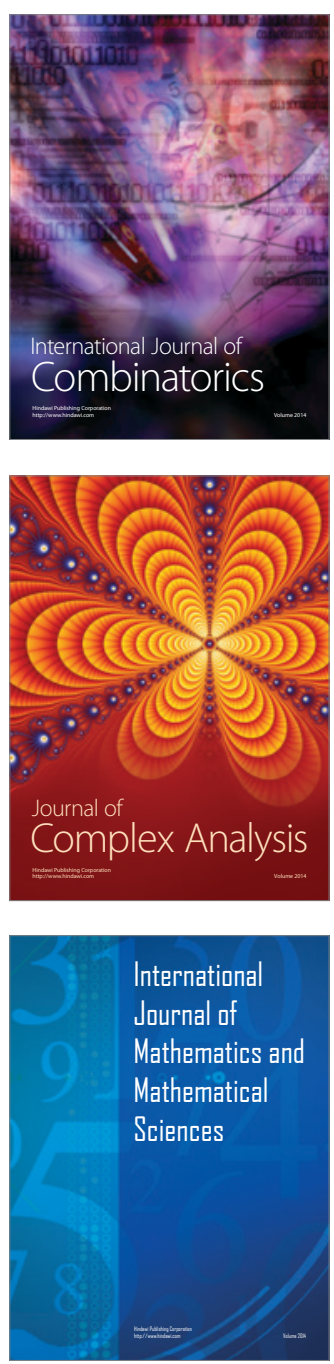
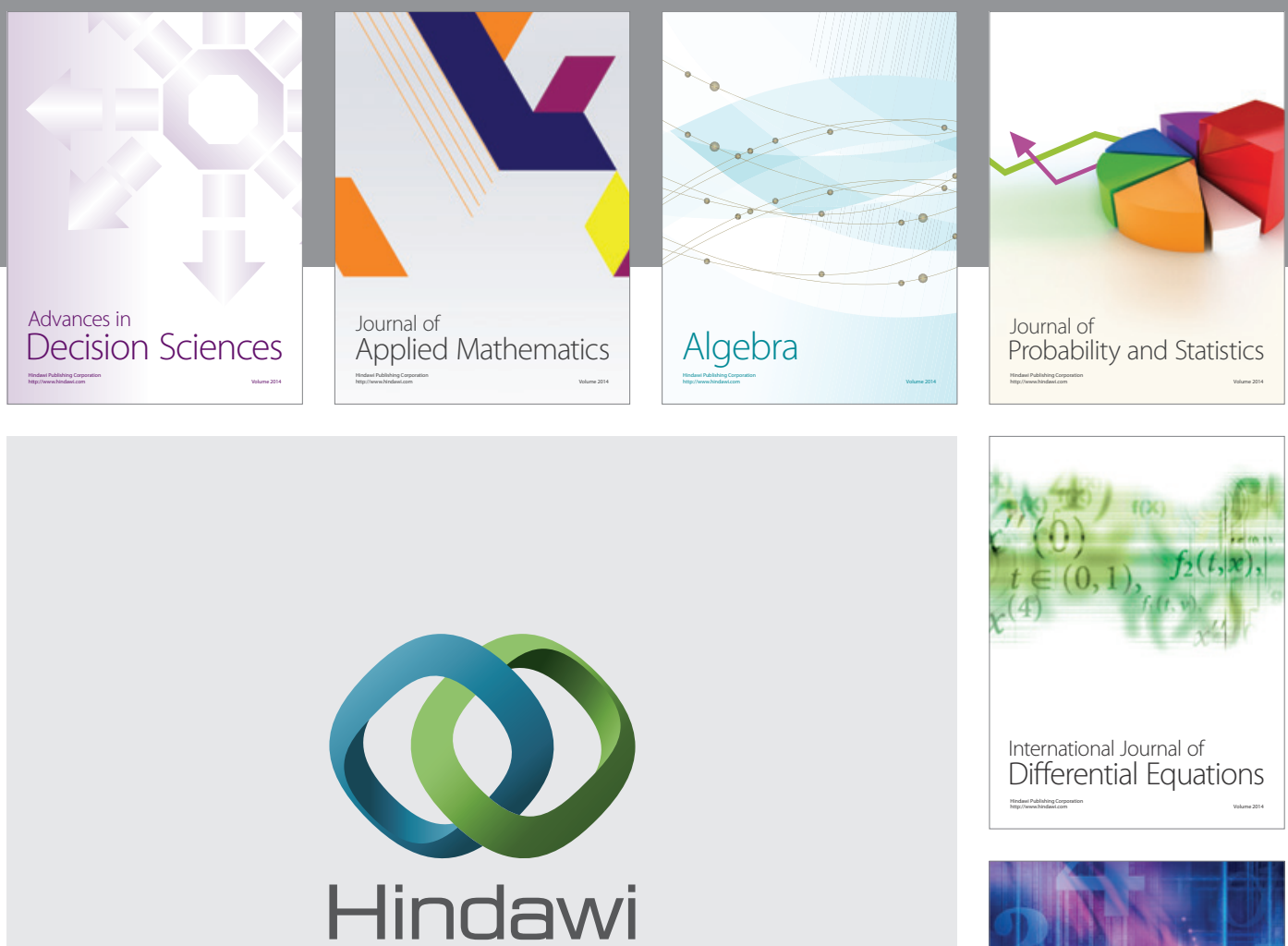

Submit your manuscripts at http://www.hindawi.com
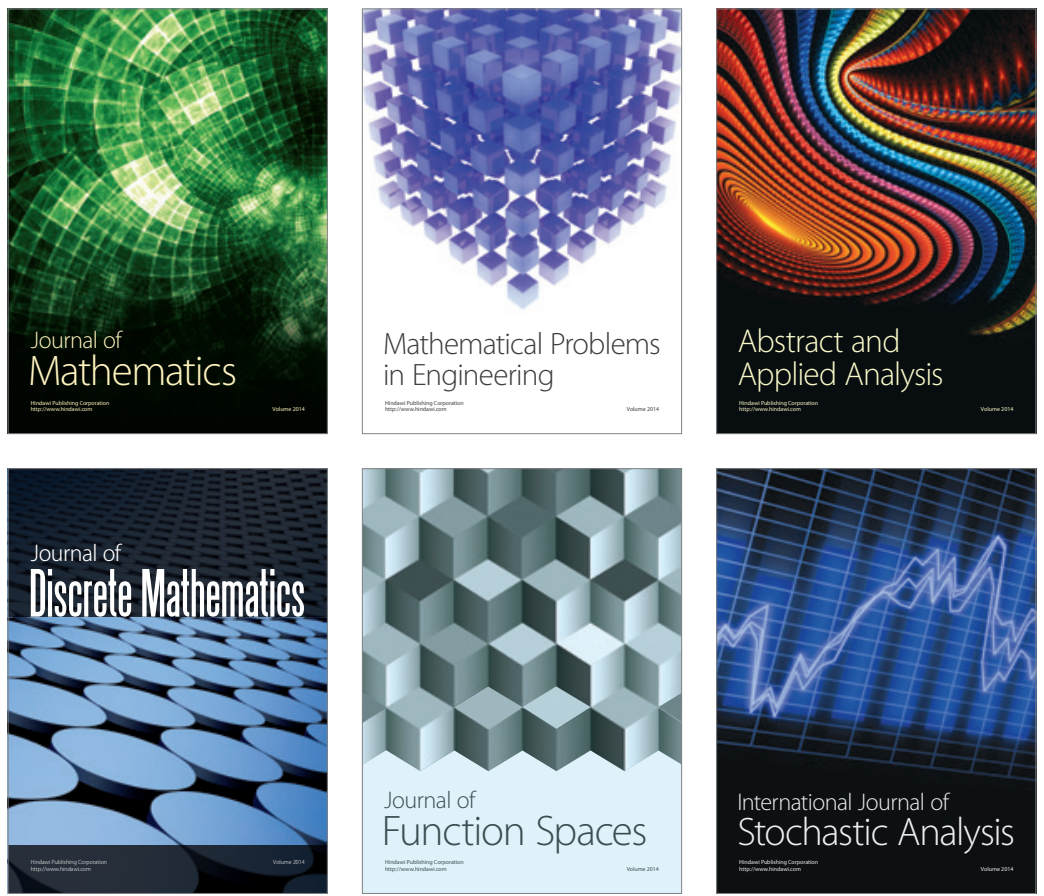

Journal of

Function Spaces




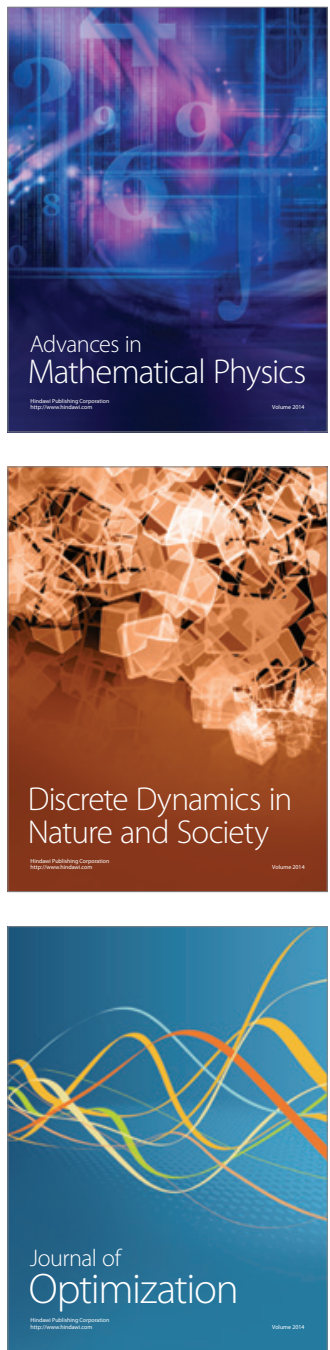